\title{
Antioxidant activity, $\alpha$-glucosidase inhibition and phytochemical profiling of Hyophorbe lagenicaulis leaf extracts
}

\author{
James William ${ }^{1}$, Peter John ${ }^{\text {Corresp., } 1}$, Muhammad Waseem Mumtaz ${ }^{\text {Corresp., }}{ }^{2}$, Ayoub Rashid Ch ${ }^{1}$, Ahmad Adnan ${ }^{1}$, Hamid \\ Mukhtar $^{3}$, Shahzad Sharif ${ }^{1}$, Syed Ali Raza ${ }^{1}$, Muhammad Tayyab Akhtar ${ }^{3}$, Azizah Abdul Hamid ${ }^{4}$ \\ 1 Department of Chemistry, Government College University Lahore, Lahore, Pakistan \\ 2 Department of Chemistry, University of Gujrat, Gujrat, Pakistan \\ 3 Institute of Industrial Biotechnology, Government College University Lahore, Lahore, Pakistan \\ 4 Department of Food Science, Faculty of Food Science and Technology, Universiti Putra Malaysia, Seri Kembangan, Selangor, Malaysia \\ Corresponding Authors: Peter John, Muhammad Waseem Mumtaz \\ Email address: peterjohn07@hotmail.com, muhammad.waseem@uog.edu.pk
}

\begin{abstract}
Background Diabetes mellitus type II (DMT-2) is widely spread metabolic disorder both in developed and developing countries. The role of oxidative stress is well established in DMT-2 pathogenesis. The synthetic drugs for DMT-2 are associated with serious side complications. Antioxidant and $\alpha$-glucosidase inhibitory actions of phytochemicals from various plant species are considered as an alternative to synthetic drugs for DMT-2 management. The present study aimed to evaluate the antioxidant activity, $\alpha$-glucosidase inhibitory potential and phytochemical profiling of Hyophorbe lagenicaulis.
\end{abstract}

Methods The total phenolic and flavonoid contents, in vitro antioxidant activity (DPPH assay and phosphomolybedenum method) and $\alpha$-glucosidase inhibition of ultrasonicated hydroethanolic Hyophorbe lagenicaulis leaf extracts were determined spectrophotometrically. The results of DPPH assay and $\alpha-$ glucosidase inhibition were reported in terms of $\mathrm{IC}_{50}$ value. The phytochemical profiling was accomplished by UHPLC-Q-TOF/MS/MS technique.

Results and Discussion Findings leaped $60 \%$ ethanolic extract as rich fraction regarding total phenolic and flavonoid contents. The $60 \%$ ethanolic fraction was promising source of natural antioxidants and $\alpha$ glucosidase inhibitory agents as indicated by anti-radical and enzyme inibitory activities. Kaempferol, rutin, hesperetin 5-0-glucoside, kaempferol-coumaroyl-glucoside, luteolin 3-glucoside, Isorhamnetin-3-0rutinoside, trimethoxyflavone derivatives and citric acid were identified by UHPLC-Q-TOF-MS/MS. These compounds were believed to be responsible for the strong antioxidant and anti-enzymatic activity of plant extracts. The extensive metabolite profiling of $H$. lagenicaulis was carried out first time as never reported previously. The $H$. lagenicaulis might be an appropriate choice to manage diabetes mellitus in alternate way. The findings may be further exploited extensively for toxicity evaluation to proceed with functional food development having antidiabetic attributes. 
1 Antioxidant activity, a-glucosidase inhibition and phytochemical profiling of Hyophorbe 2 lagenicaulis leaf extracts

3 James William¹, Peter John*1, Muhammad Waseem Mumtaz*2, Ayoub Rashid Ch¹, Ahmad

4 Adnan$^{1}$, Hamid Mukhtar ${ }^{3}$, Shahzad Sharif 1, Syed Ali Raza1, Muhammad Tayyab Akhtar ${ }^{3}$,

5 Azizah Abdul Hamid ${ }^{4}$

6 1. Department of Chemistry, Government College University Lahore 54000, Pakistan

7 2. Department of Chemistry, University of Gujrat, Gujrat, Pakistan

8 3. Institute of Industrial Biotechnology, Government College University Lahore 54000, Pakistan

9 4. Department of Food Science, Faculty of Food Science and Technology, Universiti Putra Malaysia, Seri Kembangan, Selangor, Malaysia

11

*Email id: peterjohn@gcu.edu.pk ; muhammad.waseem@uog.edu.pk

\begin{abstract}
\end{abstract}
Background

Diabetes mellitus type II (DMT-2) is widely spread metabolic disorder both in developed and developing countries. The role of oxidative stress is well established in DMT-2 pathogenesis. The synthetic drugs for DMT-2 are associated with serious side complications. Antioxidant and $\alpha$-glucosidase inhibitory actions of phytochemicals from various plant species are considered as an alternative to synthetic drugs for DMT-2 management. The present study aimed to evaluate the antioxidant activity, $\alpha$-glucosidase inhibitory potential and phytochemical profiling of Hyophorbe lagenicaulis.

\title{
Methods
}

The total phenolic and flavonoid contents, in vitro antioxidant activity (DPPH assay and phosphomolybedenum method) and $\alpha$-glucosidase inhibition of ultrasonicated hydroethanolic Hyophorbe lagenicaulis leaf extracts were determined spectrophotometrically. The results of DPPH assay and $\alpha$-glucosidase inhibition were reported in terms of $\mathrm{IC}_{50}$ value. The phytochemical profiling was accomplished by UHPLC-Q-TOF/MS/MS technique.

\section{Results and Discussion}

Findings leaped $60 \%$ ethanolic extract as rich fraction regarding total phenolic and flavonoid contents. The $60 \%$ ethanolic fraction was promising source of natural antioxidants and $\alpha$ - 
32 glucosidase inhibitory agents as indicated by anti-radical and enzyme inibitory activities. 33 Kaempferol, rutin, hesperetin 5-O-glucoside, kaempferol-coumaroyl-glucoside, luteolin 3glucoside, Isorhamnetin-3-O-rutinoside, trimethoxyflavone derivatives and citric acid were identified by UHPLC-Q-TOF-MS/MS. These compounds were believed to be responsible for the strong antioxidant and anti-enzymatic activity of plant extracts. The extensive metabolite profiling of $H$. lagenicaulis was carried out first time as never reported previously. The $H$. lagenicaulis might be an appropriate choice to manage diabetes mellitus in alternate way. The findings may be further exploited extensively for toxicity evaluation to proceed with functional food development having antidiabetic attributes.

\section{INTRODUCTION}

Diabetes is one of the leading non-infectious diseases with multiple side complications characterized by persistent hyperglycemia due to reduced insulin secretion or action (Schwartz et al., 2016). More than 90\% diabetic patients are suffering from diabetes mellitus type 2 (DMT-2) and it is estimated that by 2035 the expansion of DMT-2 will result in 592 million diabetic patients worldwide (Guariguata et al., 2014). The huge expansion rate of DMT-2 is now considered a socio-economic burden and covers about $10 \%$ of the total health care expenditures in many countries (Pari and Saravanan, 2007). The modern life style and dietary habits are among the key factors responsible for the DMT-2 progression. These factors are associated with the production of reactive oxygen species (ROS) which in excess may generate the state of oxidative stress. The role of ROS and oxidative stress in DMT-2 progression is evident from scientific studies (Charokopou et al., 2016; Sami et al., 2017). The mechanism of action through which oxidative stress contributes to DM pathogenesis is not fully clear. However, the hyperglycemia is reported to produce free radicals which impair the function of antioxidant enzymes in plasma (Asmat et al., 2016). The oxidative stress also impairs the insulin secretion, alteration in glucose uptake, abnormal glucose release form liver and mediation of metabolic pathways (Akash et al., 2011). The natural antioxidants in body are mainly enzymes which include superoxide dismutase, glutathione peroxidases and reductases. The vitamin A and E are also important endogenous antioxidants which substantially reduce the level of oxidative stress (Madhikarmi \& Murthy 2014). The glycation of antioxidant enzymes also alters the structure based function of enzymes to increase the chances of damage by ROS (Sing et al., 2014). The lipid oxidation and glutathione metabolism impairments are used as biomarkers for DM and 
oxidative stress usually alters this to initiate DMT-2. Antioxidants are believed to encounter ROS to reduce level of oxidative stress to prevent development of DMT-2. High levels of ROS are involved in glycation of proteins, lipid peroxidation and glucose oxidation and these collectively impart in DMT-2 development and related disorders (Asmat et al., 2016). The elimination of ROS or reduction in level of oxidative stress may diminish the chances of DMT-2 pathogenesis and prolongation by improving the intra cellular antioxidant defense (Ceriello \&Testa 2009). The antioxidants based therapy is considered as promising approach to treat DMT-2 as antioxidants effectively scavenge the free radicals and ROS to prevent DM pathogenesis and related complications (Rahimi et al., 2016).

Many synthetic drugs are available to manage diabetes but the side effects associated with these compounds are matter of keen concern (Chaudhury et al., 2017). Health related drawbacks of synthetic medicines emphasize on the need to develop alternate treatments for DMT-2. Plants are rich source of natural, safe and potent phytochemicals of medicinal attributes to treat chronic ailments. The many of natural bioactive ingredients in plants are also associated with $\alpha$ glucosidase inhibition. The $\alpha$-glucosidase inhibitors restrict the hydrolysis of carbohydrates (Oligosaccahrides, trisaccharides and disaccharides) in intestine and slow down their absorption, hence limit the postprandial glucose level (Rouzbehan et al., 2017). Plants also contain natural antioxidants which encounter the exceeding ROS levels in body to reduce the risks of DMT-2 pathogenesis and progression (Zaid et al., 2015). Therefore search for $\alpha$-glucosidase inhibitors from plants for DMT-2 management is workable, safe, reliable and cost effective approach.

Family Arecaceae contains more than 189 genera, 3000 species and some species are very rich in antioxidants and other functional molecules. Plants from family Arecaceae have been studied for their potential medicinal use however many species are still needed to explore for their hidden biological and pharmacological role (Govaerts and Dransfield, 2005). Hyophorbe lagenicaulis (H. lagenicaulis ) of family Arecaceae is among such plants which are not completely studied for their potential biological activities (Elgindi et al., 2016). Inspite of effective role of $H$. lagenicaulis in folk medicines, no scientific evidence is available on biological activities and phytochemical distribution in this plant. The current work was performed to evaluate the in vitro antioxidant and antidiabetic potential of $H$. lagenicaulis. The metabolite profiling of leaf extract of H. lagenicaulis was also carried out.

MATERIAL AND METHODS 
94

95

96

97

98

99

100

101

102

103

104

105

106

107

108

109

110

111

112

113

114

115

116

117

118

119

120

121

122

123

124

\section{Collection of plant material}

The plant material was collected from Lahore, Pakistan and was identified from Department of Botany, GC University Lahore.

\section{Green extract preparation}

Quenching of fresh leaves was done in liquid nitrogen and grinded to fine powder to enhance surface area. The obtained powder was lyophilized using a freeze-dryer (Christ Alpha 1-4 LD (Germany) and subjected to hydroethanolic solvent compositions (Ethanol, 100\%, 80\%, 60\%, $40 \%, 20 \%$ ) for 48 hours. Mixtures were sonicated at soniprep 150 disintegrator below $10{ }^{\circ} \mathrm{C}$. Samples were shaken for 2 hours and filtered. The excess solvent from filtrate was removed under vacuum on rotary evaporator at $40{ }^{\circ} \mathrm{C}$. The extracts were again freeze dried for 48 hours. Extract yields (\%) were calculated and extracts were stored at $-80{ }^{\circ} \mathrm{C}$ till further use.

\section{Determination of total phenolic and flavonoid contents}

Total phenolic contents (TPC) of freeze dried leaf extracts were determined by Folin Ciocalteu reagent method with slight modification in previously reported scheme (Zhishen et al., 1999). The plant extract $(1 \mathrm{mg})$ was dissolved in methanol $(1 \mathrm{~mL})$ and $0.25 \mu \mathrm{L}$ of this was added to 1 $\mathrm{mL}$ of Folin Ciocalteu reagent. Then $2 \mathrm{~mL}$ of $10 \%$ solution of $\mathrm{Na}_{2} \mathrm{CO}_{3}$ followed by addition of 2 $\mathrm{mL}$ distilled water. The resultant mixture was stayed for $120 \mathrm{~min}$ at ambient conditions of temperature. The absorbance was noted at $765 \mathrm{~nm}$. Standard curve of gallic acid was also drawn. Results were expressed as gallic acid equivalent (GAE) mg/g dried extract (Zengin et al., 2010). Total flavonoid contents (TFC) were determined by $\mathrm{AlCl}_{3}$ colorimetric method. The $0.1 \mathrm{mg}$ of plant extract was dissolved in methanol $(2 \mathrm{~mL})$ and added by $5 \mathrm{ml}$ of distilled water. Then 0.5 $\mathrm{mL}$ of $\mathrm{NaNO}_{2}(5 \%)$ was added to mixture followed by addition of $10 \% \mathrm{AlCl}_{3}$ solution. After 10 min $\mathrm{NaOH}$ ( 1molar) was added to resultant mixture and after vigorous shaking, absorbance was measured at $510 \mathrm{~nm}$. The results were expressed as rutin equivalent $\mathrm{mg} / \mathrm{g}$ dried extract (RE mg/DE) (Zhishen et al.,1999)

\section{Antioxidant activities}

Antioxidant potential of extracts was determined by DPPH scavenging assay as reported previously with little modification (Fki et al., 2005). The $1 \mathrm{mg}$ plant extract was dissolved in methanol. The 50-200 ppm of these dilutions were added to $10 \mathrm{ml}$ of DPPH solution (0.001 molar). After 30 min incubation in dark at room temperature, absorbance was measured at 520 
$125 \mathrm{~nm}$. BHA was used as standard for comparison. All the measurements were carried out in

126 triplicate and standard deviation was applied.

127 Phosphomolybdenum complex formation method was used as per previously reported method 128 with minute modifications (Prieto et al., 1999). Initially, $250 \mu \mathrm{g} / \mathrm{mL}$ of each extract was mixed 129 with solution composed of sulphuric acid (0.6 M), ammonium molybdate $(4 \mathrm{mM})$ and $28 \mathrm{mM}$ 130 sodium phosphate. The mixtures and blank solution both were incubated at $95^{\circ} \mathrm{C}$ for 90 min at 131 water bath. After cooling, absorbance was noted at $695 \mathrm{~nm}$ wavelength. Ascorbic acid standard 132 curve was drawn and butylated hyroxyanisole (BHA) was used as standard antioxidant. The 133 results were represented as ascorbic acid equivalent per gram dried plant extract (AE/g DE).

\section{Anti- $\alpha$-glucosidase activity}

135 Inhibition potential of extracts against $\alpha$-glucosidase was measured to evaluate in vitro 136 antidiabetic potential. Various concentrations of extarcts (200 ppm) were added to phosphate 137 buffer $(70 \mu \mathrm{L}$ of $50 \mathrm{mM})$ followed by addition of $\alpha$-glucosidase ( $1 \mathrm{unit} / \mathrm{mL})$. After $10 \mathrm{~min}$ 138 incubation at $37^{\circ} \mathrm{C}, 5 \mathrm{mM}$ of $\rho$-nitrophenolglucopyranoside was added and absorbance was 139 noted at $405 \mathrm{~nm}$ after $30 \mathrm{~min}$. Acarbose was used as standard reference and results were 140 represented as $\mathrm{IC}_{50}(\mu \mathrm{g} / \mathrm{mL})$ values for each extract (Jabeen et al., 2013).

Where, Ab is absorbance of blank, As is absorbance of Sample.

\section{The $\alpha$-amylase inhibition activity}

145 The $250 \mu \mathrm{L}$ of each extract $(1.0-10 \mathrm{mg} / \mathrm{mL})$ were added to $0.02 \mathrm{M}$ sodium phosphate buffer containing porcine $\alpha$-amylase $(0.5 \mathrm{mg} / \mathrm{mL})$. The reaction mixture was incubated for $10 \mathrm{~min}$ at $25^{\circ} \mathrm{C}$. The dinitrosalicylic acid (DNS) was added to the mixture to stop the reaction. The reaction mixtures were further incubated for a time period of $5 \mathrm{~min}$ and diluted with distilled water to note absorbance at $540 \mathrm{~nm}$. A control (no extract) was also run and acarbose was used as standard enzyme inhibitory substance (Kazeem, Adamson \& Ogunwande 2013). The \% inhibition was calculated by following relationship; 
Where, Ab is absorbance of blank, As is absorbance of Sample.

156 Results were represented as $\mathrm{IC}_{50}(\mu \mathrm{g} / \mathrm{mL})$ values for each extract.

\section{UHPLC-Q-TOF-MS/MS analysis}

158 Plant extract was extracted with suitable solvent and filtered with plastic filter having $0.45 \mu \mathrm{m}$ pore size. The filtered extract sample was subjected to UHPLC-Q-TOF-MS/MS (AB Sciex 5600-1, equipped with Eksigent UHPLC system). The scanning range of $50-1200 \mathrm{~m} / \mathrm{z}$ for MS/MS (negative ionization mode), column Thermo Hypersil Gold $(100 \mathrm{~mm} \times 2.1 \mathrm{~mm} \times 3 \mu \mathrm{m})$, gradient mobile phase composition (water and acetonitrile) each having $0.1 \%$ formic acid and 5 $\mathrm{mM}$ ammonium formate was used. Gradient programming started from $10 \%$ acetonitrile to $90 \%$ acetonitrile with mobile phase flow rate of $0.25 \mathrm{~mL} / \mathrm{min}$. Desolvation temperature (TEM) was $500{ }^{\circ} \mathrm{C}$ and ion spray voltage was $-4500 \mathrm{~V}$.

\section{Statistical analysis}

The experimental findings were evaluated for statistical significance by using Statistix 10.0 software. Analysis of variance (ANOVA) was used to compare variations in treatment means to assess efficacy of treatments.

\section{RESULTS}

\section{Extract yields (\%), TPC and TFC}

172 The extract yields, TPC and TFC with respect to solvent system used for extraction are given in 173 Table I. It was revealed by the findings that solvent influenced extract yields significantly.

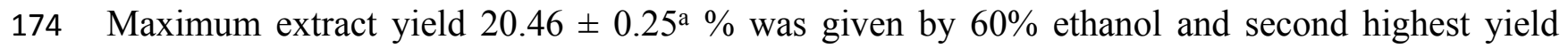
$17518.05 \pm 0.13^{\mathrm{b}} \%$ was obtained with $80 \%$ ethanol. Solvent composition not only affected the 176 extract yields but also TPC and TFC. Maximum TPC of $178.56 \pm 1.47^{\mathrm{a}} \mathrm{mg}$ GAE/g DE were 177 recovered with $60 \%$ ethanol. Similarly highest TFC of $133.96 \pm 1.19^{\mathrm{a}} \mathrm{mg}$ Rutin/g DE were 178 extracted with $60 \%$ ethanol. Efficiency of $60 \%$ ethanolic extract was significantly higher than 179 other solvent fraction for extract yield, TPC and TFC respectively $(\rho<0.05)$.

\section{Antioxidant activities}


181 The DPPH radical scavenging in terms of IC-50 value $(\mu \mathrm{g} / \mathrm{mL})$ by plant extracts in comparison

182 with BHA is represented as Figure I. Maximum radical scavenging among extracts was exhibited 183 by $60 \%$ ethanolic extract with minimum IC-50 value of $43.11 \pm 0.96 \mu \mathrm{g} / \mathrm{mL}$.

184 Total antioxidant power of extracts was determined by phosphomolybdenum methods. This 185 method involved the reduction of Mo (VI) to Mo (V) with characteristic color change due to 186 complex formation. This assay is widely used to evaluate the total antioxidant power of plant 187 extracts and compounds (Prieto et al., 1999; Rani et al., 2018).

188 The results of assay were represented in Figure II. Findings unveiled that $60 \%$ ethanolic fraction 189 exhibited maximum antioxidant power with value of $239.33 \pm 3.78^{\mathrm{b}}$ (ASE/g PE) followed by $19080 \%$ ethanolic extract $\left(189.33 \pm 2.51^{\mathrm{c}}\right.$ ASE/g DE). Statistical analysis indicated that antioxidant 191 power of BHA was significantly higher than all extracts $(\rho<0.05)$. However $60 \%$ ethanolic 192 extract was most potent among all plant extracts $(\rho<0.05)$ regarding antioxidant potential.

\section{Anti- $\alpha$ - glucosidase activity}

194 Inhibition of $\alpha$ - glucosidase enzyme reflects the in vitro antidiabetic potential which is 195 determined spectrophotometrically. The IC-50 values $(\mu \mathrm{g} / \mathrm{mL})$ of plant extracts and standard 196 drug acarbose are represented in Figure III. The comparison of extracts showed that $60 \%$ 197 ethanolic extract among all fractions possessed maximum $\alpha$-glucosidase inhibition with IC-50 198 value of $41.25 \pm 1.25 \mu \mathrm{g} / \mathrm{mL}$. The standard drug acarbose exhibited lowest IC-50 value of 25.50 $199 \pm 0.45 \mu \mathrm{g} / \mathrm{mL}$ which was significantly lower than all extracts $(\rho<0.05)$. Statistical comparison 200 further indicated that $60 \%$ ethanolic extract was significantly better than remaining extracts ( $\rho$ $201<0.05)$.

\section{The $\alpha$ - amylase inhibition}

203 The results of $\alpha$-amylase inhibition are given in Figure IV. The 60\% ethanolic extract (IC-50 $20460.58 \pm 3.24 \mu \mathrm{g} / \mathrm{mL}$ ) exhibited highest $\alpha$-amylase inhibition followed by $80 \%$ ethanolic extract 205 with IC-50 value of $77.57 \pm 2.25 \mu \mathrm{g} / \mathrm{mL}$. The $20 \%$ ethanolic extract exhibited least inhibition of 206 enzyme activity as indicated by IC-50 value $(114.00 \pm 1.88 \mu \mathrm{g} / \mathrm{mL})$. The standard compound 207 acarbose showed highest $\alpha$-glucosidase inhibition with IC-50 value of $43.37 \pm 0.75 \mu \mathrm{g} / \mathrm{mL}$. 208 Statistical analysis revealed that $60 \%$ ethanolic extract was the most potent $\alpha$-glucosidase 209 inhibitory fraction.

\section{UHPLC-Q-TOF-MS/MS analysis}


212 The efficacy of $60 \%$ ethanolic extract regarding antioxidant and $\alpha$-glucosidase inhibition

213 emphasized to explore this fraction for metabolite identification. So the $60 \%$ ethanolic extract 214 was subjected to UHPLC-Q-TOF-MS/MS analysis and identified compounds along with their 215 retention time $(\mathrm{Rt})$, fragment ions and molecular formula are listed in Table II. The main 216 chromatogram of UHPLC separation is shown as Figure V. The fragmentation pattern of 217 identified compounds is represented in Figure VI. Citric acid appeared at Rt 1.603 min with 218 characteristic parent ion peak at m/z $191[\mathrm{M}-\mathrm{H}]^{-}$and daughter ion peak at m/z 111[M-CO $\left.\mathrm{CO}_{2}-\mathrm{H}_{2} \mathrm{O}\right]^{-}$. 219 Trimethoxy flavone derivative arrived at Rt $8.972 \mathrm{~min}$ with peaks at $\mathrm{m} / \mathrm{z} 635, \mathrm{~m} / \mathrm{z} 609$ and m/z 220 300. Kaempferol was recorded at Rt $9.110 \mathrm{~min}$ with $\mathrm{m} / \mathrm{z} 285$. The fragment ion peaks at $\mathrm{m} / \mathrm{z} 151$ 221 and $\mathrm{m} / \mathrm{z} 93$ due to removal of fragment of $134 \mathrm{amu}$ and phenoyl moiety respectively. Rutin was 222 recorded at Rt $9.27 \mathrm{~min}$ with parent ion peak $\mathrm{m} / \mathrm{z} 609$. The fragment ion having $\mathrm{m} / \mathrm{z} 300$ 223 appeared due to removal of moiety of mass $309 \mathrm{amu}$. The fragment ion of $\mathrm{m} / \mathrm{z} 271$ was produced 224 due to removal of 29 amu from fragment ion m/z 300. Peak at Rt 9.689 was identified as 225 kaempferol-coumaroyl-glucoside with parent peak at $\mathrm{m} / \mathrm{z} 593$. The removal of coumaroyl 226 glucoside produced fragment ion peak at $\mathrm{m} / \mathrm{z} 285$. Leuteolin 3-glucoside was identified at Rt 2279.724 with parent ion peak at $\mathrm{m} / \mathrm{z} 447$. Removal of glucose from parent ion generated leuteolin 228 characteristic peak at m/z 285. Hesperetin 5-O-glucoside was identified at Rt 9.433 with parent 229 peak at m/z 463[M-H] $]^{-}$and fragment ions at m/z 301[M-glucose-H]', m/z 271[m/z 301-CH ${ }_{2} \mathrm{O}-$ $230 \mathrm{H}]^{-} \mathrm{m} / \mathrm{z} 255\left[\mathrm{~m} / \mathrm{z} 301-\mathrm{C}_{2} \mathrm{H}_{2} \mathrm{O}-\mathrm{H}\right]^{-}, \mathrm{m} / \mathrm{z} 149\left[\mathrm{~m} / \mathrm{z} \text { 255- } \mathrm{C}_{6} \mathrm{H}_{2} \mathrm{O}_{2}-\mathrm{H}\right]^{-}$respectively. Isorhamnetin 3-O231 rutinoside appeared at Rt 9.995 with $\mathrm{m} / \mathrm{z}$ 623. The further collision resulted in fragment ions $\mathrm{m} / \mathrm{z}$ $232315[\mathrm{M}-318-\mathrm{H} \text { amu }]^{-}, \mathrm{m} / \mathrm{z} 300$ [m/z 315-CH $\left.3-\mathrm{H}\right]^{-}$and m/z 284[m/z 315- $\left.\mathrm{CH}_{3} \mathrm{O}-\mathrm{H}\right]^{-}$.

233

\section{DISCUSSION}

235 The polarity of the solvent system used for extraction might be the decisive factor for enhanced 236 productivity (Chew et al., 2011). Phenolic and flavonoid compounds present in plants are 237 associated with medicinal properties. Higher concentration of both phenolics and flavonoids 238 triggers the pharmaceutical and biological attributes of a particular plant (Baba and Malik, 2015; 239 Shreshtha et al., 2017). The discrimination in TPC and TFC was probably due to solvent 240 polarity interaction with heterogeneous structural features of phytochemicals. The promising 241 antioxidant activity (DPPH and phosphomolybdenum complex method) was exerted by extracts 242 The proton transfer from phenolic compound to DPPH free radical was reported as the possible 
243 mechanism in free radical scavenging process (Liang and Kitts, 2014). The proton and electron

244 transfer from antioxidants to Mo(VI) resulted in loss of blue coloration to decrease the intensity 245 of absorbance. The reduction in absorbance was used to assess the antioxidant potential (Prieto 246 et al., 1999). The antioxidant potential of plant extracts is directly proportional to the 247 concentration and quality of phytochemicals including phenolics and flavonoids (Liew et al., 248 2018). The high $\alpha$-glucosidase inhibitory action of $60 \%$ ethanolic extract was probably due to its 249 high phenolic and flavonoid contents. Many of plant based bioactive ingredients are well known $250 \alpha$-glucosidase inhibitors and this potential may be exploited to manage DMT-2 (Yin et al., 251 2014). The $60 \%$ ethanolic extract might be a rich source of natural $\alpha$-glucosidase inhibitors. The 252 anti $\alpha$ - glucosidase activity exhibited by natural inhibitors was probably due to active site 253 occupation by a particular inhibitor molecule to restrict the mode of enzymatic action by 254 structural modification (Martinez-Gonzalez et al., 2017). Citric acid and other identified 255 compounds of flavonoid origin are well known antioxidants (Rostamzad et al., 2011). The antioxidant activities of these identified compounds were due to the interaction of phenolic groups and related structural features with ROS and other free radicals (Aadesariya et al., 2017). The antioxidant activities of plants are known as decisive factor to control ROS and to eliminate state of oxidative stress. The reduction in oxidative stress can improve the physiological status to avoid DM pathogenesis and prolongation (Singh et al., 2018). The identified compounds in addition to antioxidant potential, were also reported to be associated with antidiabetic potential. The kaempferol and rutin, both flavonoids were proved to inhibit the $\alpha$-glucosidase activity to control glucose homeostasis. (Pereira et al., 2011). Another study reported the comparative evaluation of anti- $\alpha$-glucosidase activity of kaempferol and quercetin. The findings revealed that kaempferol due to low IC-50 value was more efficient $\alpha$-glucosidase inhibitor than quercetin 266 (Dewi and Maryani, 2015). Rutin is a widely distributed polyphenolic flavonoid of plants. 267 Previous reports also highlighted the effective contribution of rutin against $\alpha$-glucosidase 268 activity, diabetes and obesity (Jo et al., 2009; Habtemariam and Lentini, 2015). Luteolin and its derivatives were reported to have promising anti- $\alpha$-glucosidase inhibition potential even higher than acarbose suggesting it as a functional tool to control postprandial hyperglycemia (Kim et al., 2000). Isorhamnetin 3-O-rutinoside a flavonoid, was reported as perfect $\alpha$-glucosidase inhibitor with significantly low IC-50 values (Yin et al., 2014). The $\alpha$-glucosidase inhibitory activity of acarbose is well established but some gastrointestinal problems also lie with it (Van de Laar FA 
274 2008). The acarbose was proved as competitive inhibitor of $\alpha$-glucosidase while plant extracts

275 having phenolics were reported to possess non-competitive inhibition of dietary enzyme. The 276 non-competitive mode provided multiple site interactions of phenolics with $\alpha$-glucosidase rather

277 than limited binding as in case of acarbose. In contrast to acarbose, $\alpha$-glucosidase inhibition by 278 phenolics in plant extracts does not depend upon the substrate concentration (Zhang et al., 2015). 279 A recent study evaluated the phenolic contents, flavonoids, antioxidant and antidiabetic activities 280 of hydroethanolic leaf extract of Conocarpus erectus. The study supported the linkage between 281 polyphenol based antioxidant activity and hypoglycemic potential of extract (Raza et al., 2018). 282 Another investigation revealed that phytochemicals from plants not only reduce the blood 283 glucose level during diabetes but also improves the hematological parameters (Sudasinghe et al., 284 2018). The antioxidant and anti- $\alpha$-glucosidase potentials of $H$. lagenicaulis extracts were 285 probably due to synergic behavior commonly observed with biologically functional plant 286 extracts (Adamska-Patruno, 2018). The presence of high value bioactives in plants supports the 287 efforts being made in search of safe and healthy therapeutic approaches for DMT-2 management.

288 The study confirmed the antioxidant and antidiabetic potential of $H$. lagenicaulis leaves. The 289 findings may be helpful to move for the reduction in socioeconomic burden, build by DMT-2.

\section{Conclusion}

291 The promissing antioxidant activity and $\alpha$-glucosidase inhibition by $H$. lagenicaulis plant 292 extracts were probably due to presence of kaempferol, rutin, isorhamnetin and luteolin 293 derivative. The findings provided us leads to proceed for functional food development having 294 antidiabetic attributes. Further in vivo studies may be carried out to support the findings of 295 current study and to evaluate the toxicity.

\section{REFERENCES}

Aadesariya MK, Ram VR, Dave PN. 2017. Evaluation of antioxidant activities by use of various extracts from Abutilon pannosum and Grewia tenax leaves in the kachchh region. MOJ Food Processing \& Technology 17(1):359 2018. A synergistic formulation of plant extracts decreases postprandial glucose and insulin peaks: results from two randomized, controlled, cross-over studies using real-world meals. Nutrients 10(8): 956 DOI 10.3390/nu10080956. 
305

306

307

308

309

310

311

312

313

314

315

316

317

318

319

320

321

322

323

324

325

326

327

328

329

330

331

332

333

334

335

Akash M, Rehman K, Rasool F, Sethi A,Abrar M, Irshad A, Abid A, Murtaza G. 2011. Alternate therapy of type 2 diabetes mellitus (T2DM) with Nigella (Ranunculaceae). Journal Medicinal Plant Research 5:6885-6889.

Asmat U, Abad K, Ismail K. 2016. Diabetes mellitus and oxidative stress-a concise review. Saudi Pharmaceutical Journal 24(5): 547-553.

Baba SA, Malik SA. 2015. Determination of total phenolic and flavonoid content, antimicrobial and antioxidant activity of a root extract of Arisaema jacquemontii Blume. Journal of Taibah University of Science. 9(4): 449-454.

Ceriello A, Testa R. 2009. Antioxidant anti-inflammatory treatment in type 2 diabetes. Diabetes care 32(suppl 2): S232-S236

Charokopou M, Sabater F, Townsend R, Roudaut M, McEwan P, Verheggen B. 2016. Methods applied in cost-effectiveness models for treatment strategies in type 2 diabetes mellitus and their use in Health Technology Assessments: a systematic review of the literature from 2008 to 2013. Current Medical Research \& Opinion 32(2):207-218.

Chaudhury A, Duvoor C, Dendi R, Sena V, Kraleti S, Chada A, Montales MT. 2017. Clinical review of antidiabetic drugs: Implications for type 2 diabetes mellitus management. Frontiers in Endocrinol. 2017; 8(6) DOI 10.3389/fendo.2017.00006

Chew K, Khoo M, Ng S, Thoo Y, Wan Aida W, Ho C. 2011. Effect of ethanol concentration, extraction time and extraction temperature on the recovery of phenolic compounds and antioxidant capacity of Orthosiphon stamineus extracts. International Food Research Journal 18(4):1427-1435.

Dewi RT, Maryani F. 2015. Antioxidant and $\alpha$-glucosidase inhibitory compounds of Centella Asiatica. Procedia Chemistry 17: 147-152.

Elgindi MR, Singab AE-NB, Aly SH, Mahmoud II. 2016. Phytochemical investigation and antioxidant activity of Hyophorbe verschaffeltii (Arecaceae). Journal of Pharmacognosy \& Phytochemistry 5(2):39-46.

Fki I, Allouche N, Sayadi S. 2015. The use of polyphenolic extract, purified hydroxytyrosol and 3, 4-dihydroxyphenyl acetic acid from olive mill wastewater for the stabilization of refined oils: a potential alternative to synthetic antioxidants. Food Chemistry 93(2): 197-204.

Govaerts R, Dransfield J. 2005. World checklist of palms: Royal Botanic Gardens. 1(1, 2): 1483, 1-529. MIM, Deurne. 
336 Guariguata L, Whiting DR, Hambleton I, Beagley J, Linnenkamp U, Shaw JE. 2014. Global 337 estimates of diabetes prevalence for 2013 and projections for 2035. Diabetes Research \& 338 Clinical Practice. 103(2):137-149.

339

340

341

342

Habtemariam S, Lentini G. 2015. The therapeutic potential of rutin for diabetes: an update. Mini Reviews in Medicinal Chemistry 15(7):524-528 DOI 10.2174/138955751507150424103721

Jabeen B, Riaz N, Saleem M, Naveed MA, Ashraf M, Alam U, Jabbar A. 2013. Isolation of natural compounds from Phlomis stewartii showing $\alpha$-glucosidase inhibitory activity. Phytochemistry 96: 443-448 DOI 10.1016/j.phytochem.2013.09.015

Jo S, Ka E, Lee H, Apostolidis E, Jang H, Kwon Y. 2009. Comparison of antioxidant potential and rat intestinal a-glucosidases inhibitory activities of quercetin, rutin, and isoquercetin. International Journal of Applied Research 62(4):52-60.

Kazeem M.,Adamson J, Ogunwande I. 2013. Modes of inhibition of $\alpha$-amylase and $\alpha$ glucosidase by aqueous extract of Morinda lucida Benth leaf. BioMed Research International 2013 DOI 10.1155/2013/527570

Kim JS, Kwon CS, SoN KH. 2000. Inhibition of alpha-glucosidase and amylase by luteolin, a flavonoid. Bioscience Biotechnology \& Biochemistry 64(11):2458-2461 DOI $\underline{10.1271 / \mathrm{bbb} .64 .2458}$

Madhikarmi NL, Murthy KRS. 2014. Antioxidant enzymes and oxidative stress in the erythrocytes of iron deficiency anemic patients supplemented with vitamins. Iranian Biomedical Journal 18(2): 82-87.

Liang N, Kitts DD. 2014. Antioxidant property of coffee components: assessment of methods that define mechanisms of action. Molecules 19(11): 19180-19208.

Liew SS, Ho WY, Yeap SK, Sharifudin SAB. 2018. Phytochemical composition and in vitro antioxidant activities of Citrus sinensis peel extracts. PeerJ 6: e5331.

Martinez-Gonzalez AI, Alvarez-Parrilla E, Díaz-Sánchez ÁG, de la Rosa LA, Núñez-Gastélum J A, Vazquez-Flores AA, Gonzalez-Aguilar GA. 2017. In vitro inhibition of pancreatic lipase by polyphenols: a kinetic, fluorescence spectroscopy and molecular docking study. Food Technology \& Biotechnology 55(4):519-530.

Pari L, Saravanan R. 2007. Beneficial effect of succinic acid monoethyl ester on erythrocyte membrane bound enzymes and antioxidant status in streptozotocin-nicotinamide induced type 2 diabetes. Chemico-Biological Interactions 169(1): 15-24. 
367 Pereira DF, Cazarolli LH, Lavado C, Mengatto V, Figueiredo MSRB, Guedes A, Silva FRMB. 368 2011. Effects of flavonoids on $\alpha$-glucosidase activity: potential targets for glucose 369 homeostasis. Nutrition 27(11):1161-1167 DOI 10.1016/j.nut.2011.01.008

370

371

372

373

374

375

376

377

378

379

380

381

382

383

384

385

386

387

388

389

390

391

392

393

394

395

396

397

Prieto P, Pineda M, Aguilar M. 1999. Spectrophotometric quantitation of antioxidant capacity through the formation of a phosphomolybdenum complex: specific application to the determination of vitamin E. Analytical Biochemistry 269(2):337-341 DOI $\underline{10.1006 / a b i o .1999 .4019}$

Rahimi-Madiseh M, Malekpour-Tehrani A, Bahmani M, Rafieian-Kopaei M. 2016. The research and development on the antioxidants in prevention of diabetic complications. Asian Pacific Journal of Tropical Medicine 9(9): 825-831 DOI 10.1016/j.apjtm.2016.07.001

Rani R., Arora S, Kaur J, Manhas RK. 2018. Phenolic compounds as antioxidants and chemopreventive drugs from Streptomyces cellulosae strain TES17 isolated from rhizosphere of Camellia sinensis. BMC Complementary and Alternative Medicine 18(1): 82 DOI $\underline{10.1186 / \mathrm{s} 12906-018-2154-4}$

Raza SA, Chaudhary AR, Mumtaz MW Ghaffar A, Adnan A, Waheed A. 2018. Antihyperglycemic effect of Conocarpus erectus leaf extract in alloxan-induced diabetic mice. Pakistan Journal of Pharmaceutical Sciences 31(2): 637-642

Rostamzad H, Shabanpour B, Kashaninejad M, Shabani A. 2011. Antioxidative activity of citric and ascorbic acids and their preventive effect on lipid oxidation in frozen Persian sturgeon fillets. Latin American Applied Research 41(2):135-140.

Rouzbehan S, Moein S, Homaei A, Moein MR. 2017. Kinetics of $\alpha$-glucosidase inhibition by different fractions of three species of Labiatae extracts: a new diabetes treatment model. Pharmaceutical Biology 55(1):1483-488 DOI 10.1080/13880209.2017.1306569

Sami W, Ansari T, Butt NS, Ab Hamid MR. 2017. Effect of diet on type 2 diabetes mellitus: A review. International Journal Health Sciences 11(2): 65-71.

Schwartz SS, Epstein S, Corkey BE, Grant SF, Gavin JR, Aguilar RB. 2016. The time is right for a new classification system for diabetes: rationale and implications of the $\beta$-cell-centric classification schema. Diabetes Care 39(2):179-186 DOI 10.2337/dc15-1585

Shreshtha S, Anushi J, Joshi AN, Joshi N, Anupma H. 2017. Study of total phenol, flavonoid contents and phytochemical screening of methanolic crude extracts of two weed plants. Annals of Plant Sciences 6(6):1645-1648 DOI https://doi.org/10.21746/1651-1654 
398 Singh M, Jha A, Kumar A, Hettiarachchy N, Rai AK, Sharma D. 2014. Influence of the solvents 399 on the extraction of major phenolic compounds (punicalagin, ellagic acid and gallic acid) and 400 their antioxidant activities in pomegranate aril. Journal of Food Science and 401 Technology 51(9):2070-2077 DOI 10.1007/s13197-014-1267-0

402 Singh J, Parasuraman S, Kathiresan S. 2018. Antioxidant and antidiabetic activities of 403 404 405 406 methanolic extract of Cinnamomum cassia. Pharmacognosy Research 10(3): 237-242 DOI $10.4103 /$ pr.pr_162_17

Sudasinghe, Hasani Prabodha, Dinithi C. Peiris. 2018. Hypoglycemic and hypolipidemic activity of aqueous leaf extract of Passiflora suberosa L.PeerJ 6: e4389

Van de Laar FA. 2008. $\alpha$-glucosidase inhibitors in the early treatment of type 2 diabetes. Vascular Health Risk \& Management 4:1189-1195.

Yin Z, Zhang W, Feng F, Zhang Y, Kang W. $\alpha$-Glucosidase inhibitors isolated from medicinal plants. Food Sci Human Well. 2014; 3(3):136-74.

Zaid H, Saad B, Mahdi AA, Tamrakar AK, Haddad PS, Afifi FU. 2015. Medicinal plants and natural active compounds for diabetes and/or obesity treatment. Evidence Based Complementary \& Alternative Medicine 2015 DOI 10.1155/2015/469762

Zengin G, Cakmak YS, Guler GO and Aktumsek A. 2010. In vitro antioxidant capacities and fatty acid compositions of three Centaurea species collected from Central Anatolia region of Turkey. Food Chemistry Toxicology 48(10):2638-2641. DOI 10.1016/j.fct.2010.06.033

Zhang H, Wang G, Dong J. 2015. Inhibitory properties of aqueous ethanol extracts of propolis on alpha-glucosidase. Evidence-Based Complementary and Alternative Medicine 2015: DOI $\underline{10.1155 / 2015 / 587383}$

420

421

422

423

424

425

426

427

428

Zhishen J, Mengcheng T, Jianming W. 1999. The determination of flavonoid contents in mulberry and their scavenging effects on superoxide radicals. Food Chemistry 64(4):555-559.

\section{List of figures}

Figure I- DPPH radicals scavenging activity in terms of IC-50 value for plant extracts and BHA. Figure II- Antioxidant power assay (ASE/g PE) for determination of antioxidant activity of plant extracts and BHA

Figure III- The IC-50 values for $\alpha$-glucosidase inhibitory potential of extract fractions and acarbose

Figure IV-The IC-50 values for $\alpha$-amylase inhibitory potential of extract fractions and acarbose 
429 Figure V- Main chromatogram of $H$. lagenicaulis (UHPLC) indicating the peaks of eluted 430 compounds

431 Figure VI- Fragmentation pattern of identified compounds with respective $\mathrm{m} / \mathrm{z}$ values 
Figure 1

DPPH radicals scavenging activity in terms of IC-50 value for plant extracts and BHA.

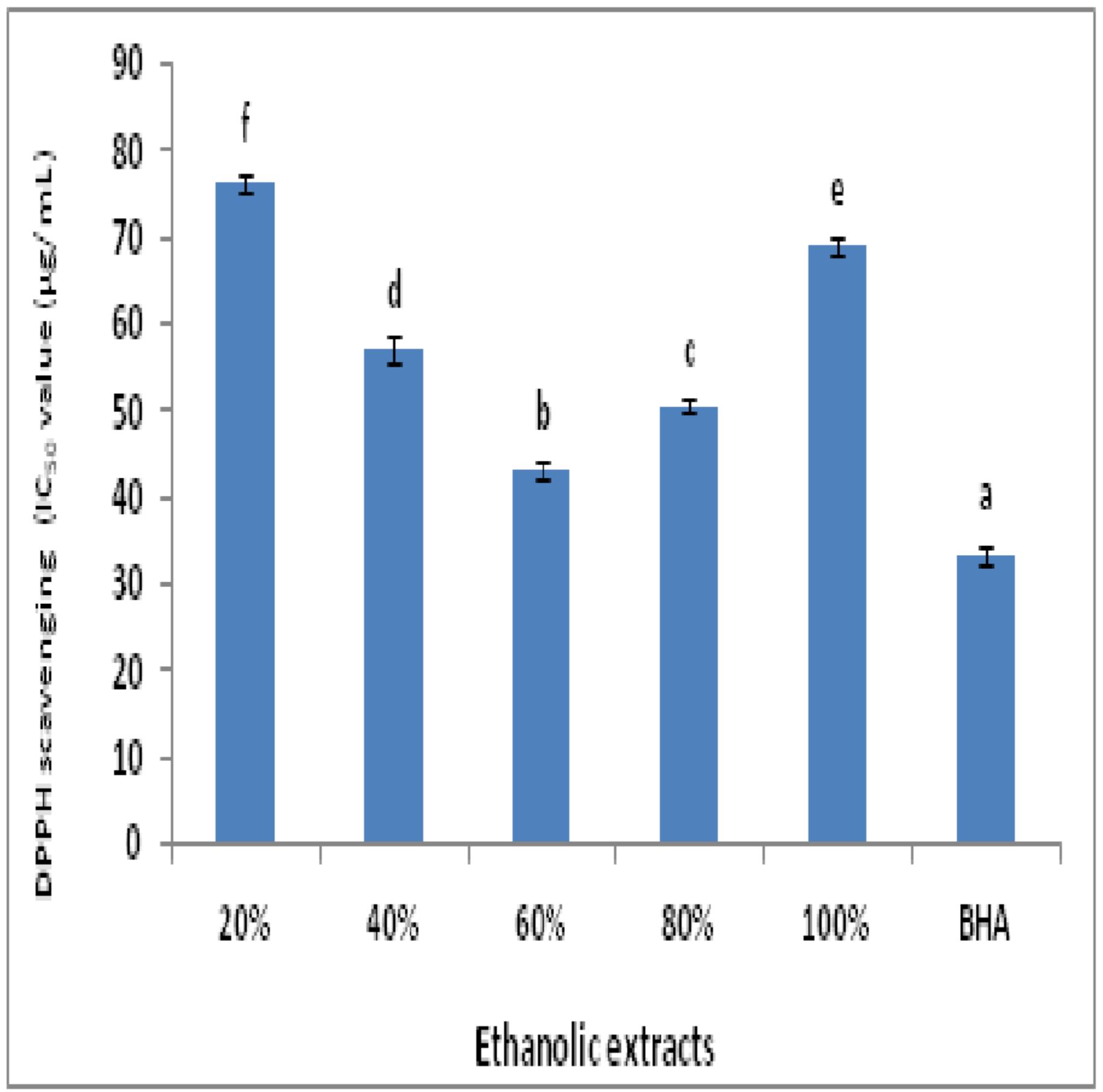


Figure 2

Antioxidant power assay (ASE/g PE) for determination of antioxidant activity of plant extracts and BHA

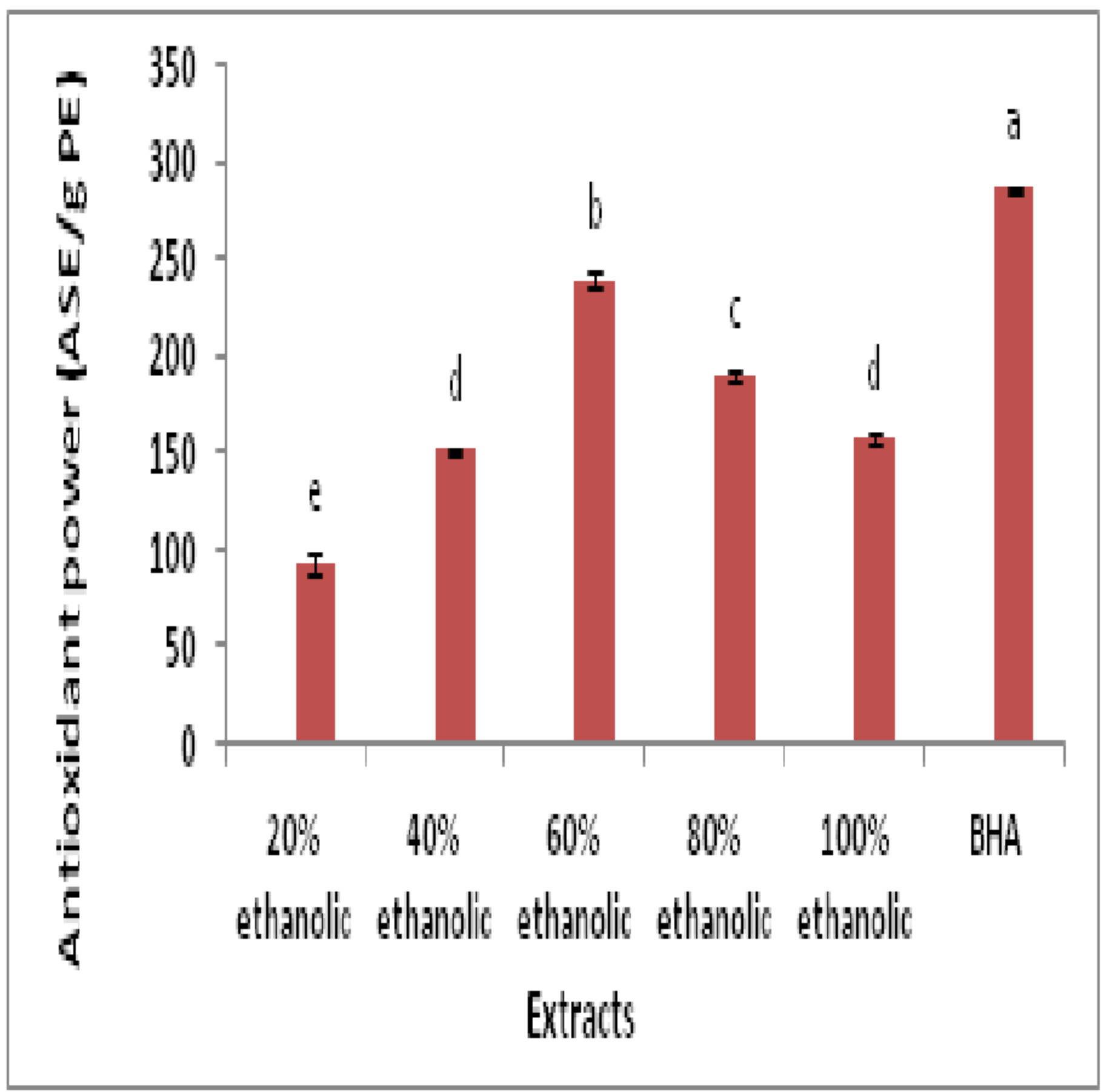


Figure 3

The IC-50 values for $\alpha$-glucosidase inhibitory potential of extract fractions and acarbose
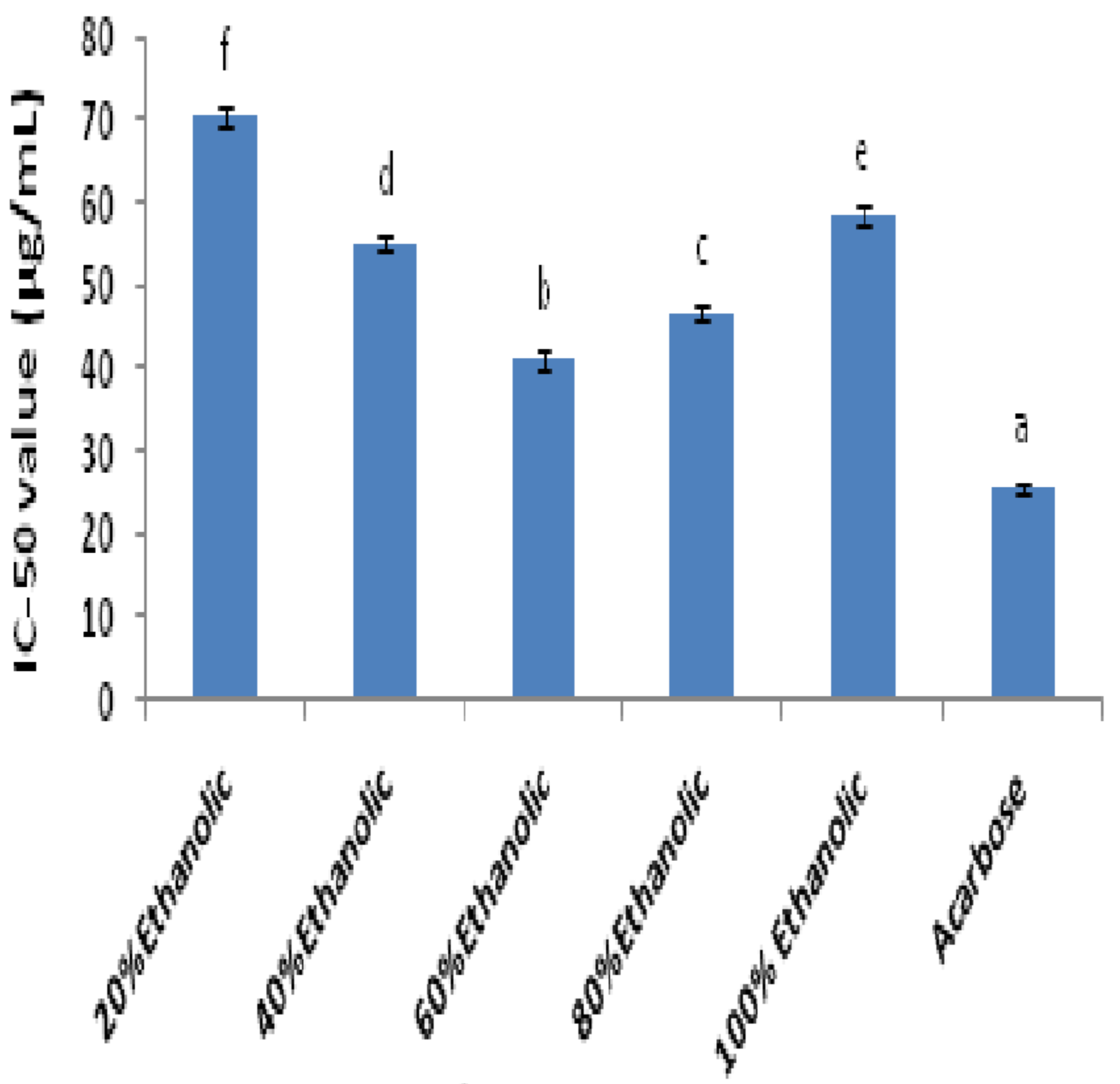

Leat extracts 
Figure 4

The IC-50 values for $\alpha$-amylase inhibitory potential of extract fractions and acarbose

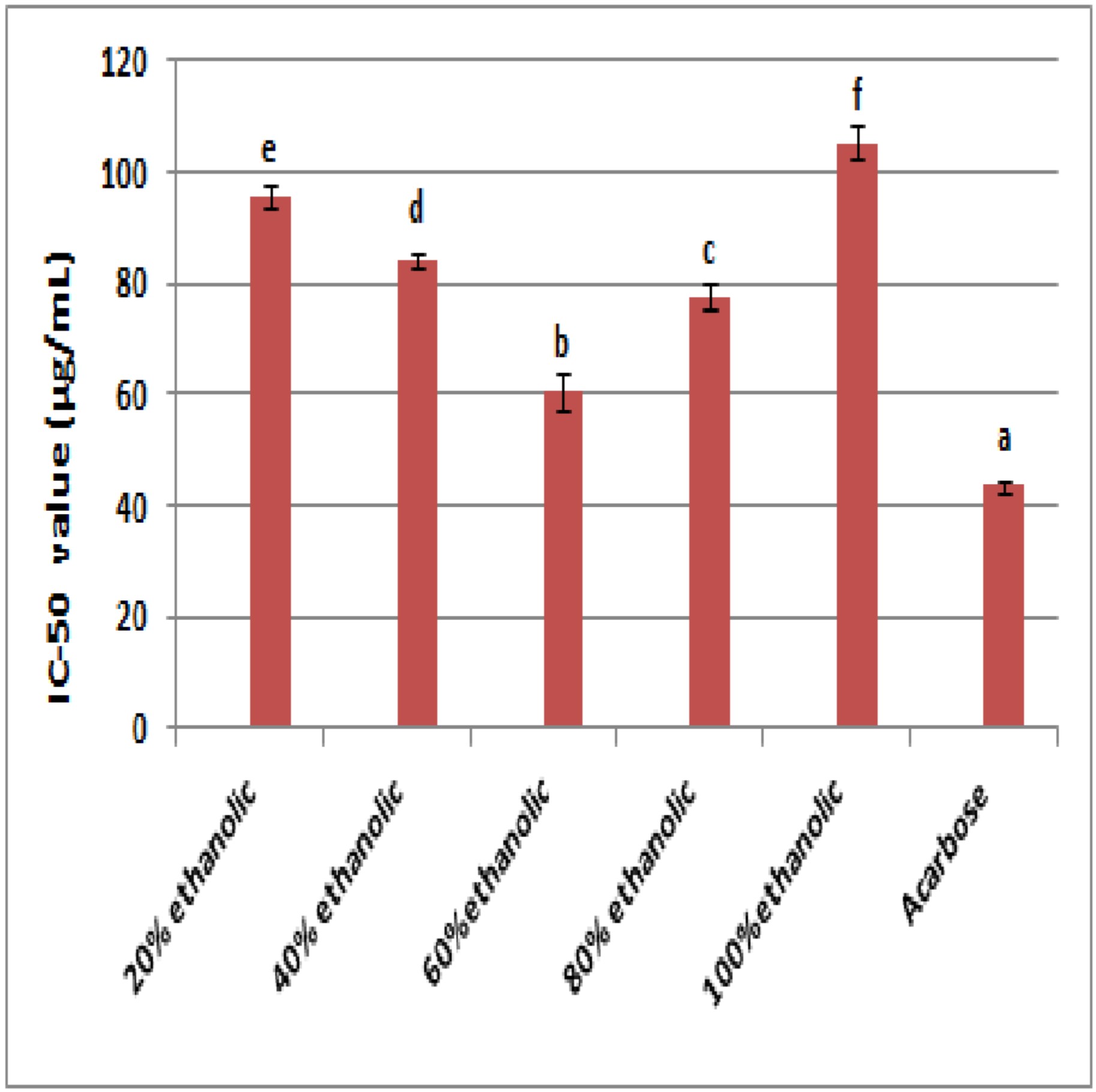


Figure 5

Main chromatogram of $H$. lagenicaulis (UHPLC) indicating the peaks of eluted compounds

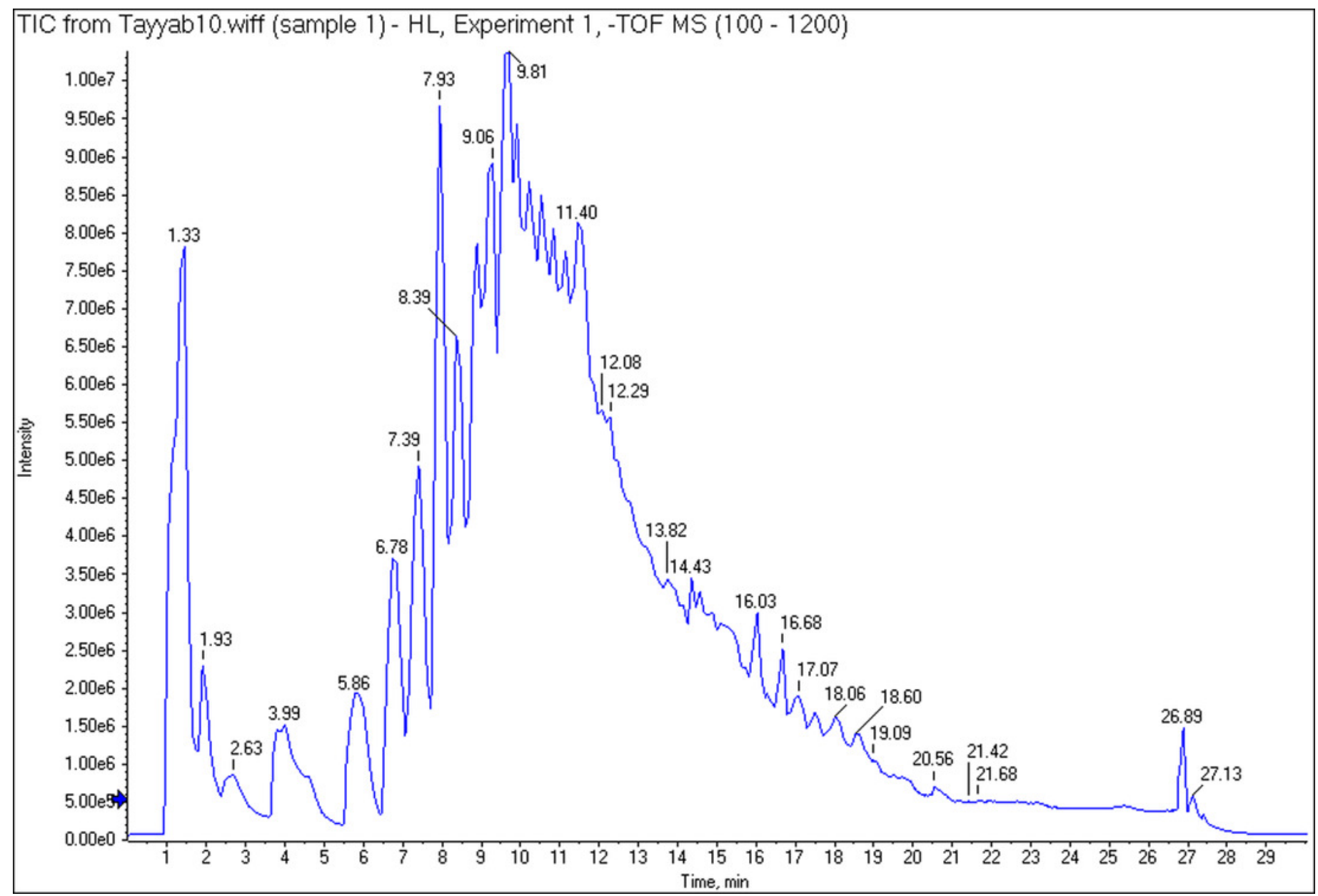


Figure 6

Fragmentation pattern of identified compounds with respective $\mathrm{m} / \mathrm{z}$ values
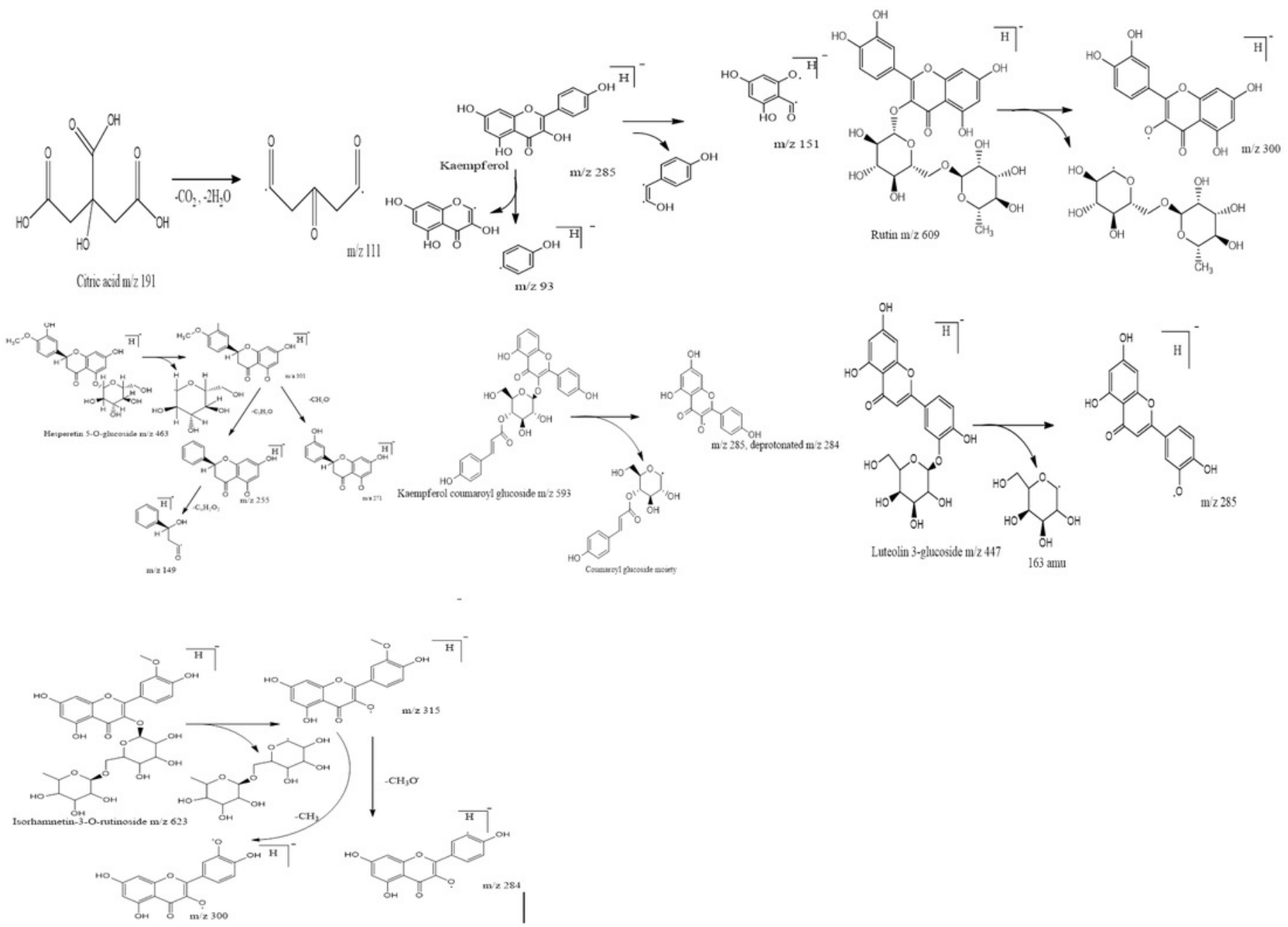


\section{Table 1 (on next page)}

Extract yields, TPC and TFC from leaves of H.lagenicaulis fractions 
1 Table I- Extract yields, TPC and TFC from leaves of H.lagenicaulis fractions

\begin{tabular}{lccc}
\hline Solvent composition & Extract yield (\%) & $\begin{array}{l}\text { TPC in mg GAE/g TFC in mg Rutin/g } \\
\text { DE }\end{array}$ & \multicolumn{2}{c}{ DE } \\
\hline & & & \\
$20 \%$ Ethanol & $14.31 \pm 0.2^{\mathrm{de}}$ & $78.09 \pm 1.36^{\mathrm{d}}$ & $68.94 \pm 1.61^{\mathrm{e}}$ \\
$40 \%$ Ethanol & $16.33 \pm 0.32^{\mathrm{c}}$ & $109.63 \pm 1.67^{\mathrm{c}}$ & $92.02 \pm 1.72^{\mathrm{d}}$ \\
$60 \%$ Ethanol & $20.46 \pm 0.25^{\mathrm{a}}$ & $178.56 \pm 1.47^{\mathrm{a}}$ & $133.96 \pm 1.19^{\mathrm{a}}$ \\
$80 \%$ Ethanol & $18.05 \pm 0.13^{\mathrm{b}}$ & $144.67 \pm 2.31^{\mathrm{b}}$ & $115.51 \pm 0.90^{\mathrm{b}}$ \\
$100 \%$ Ethanol & $15.10 \pm 0.15^{\mathrm{d}}$ & $109.62 \pm 0.44^{\mathrm{c}}$ & $100.90 \pm 1.59^{\mathrm{c}}$ \\
\hline
\end{tabular}

2 Results were represented with standard deviation values $( \pm)$ and significant level was indicated 3 by letter as superscript.

4 


\section{Table 2 (on next page)}

Peak assignments for identified compounds by UHPLC-MS/MS in negative mode 
1 Table II- Peak assignments for identified compounds by UHPLC-MS/MS in negative mode

\begin{tabular}{|c|c|c|c|c|c|}
\hline Sr. No & Name of Compound & Rt (min) & $\begin{array}{l}\text { Molecular ion } \\
\text { peak }(\mathrm{m} / \mathrm{z})\end{array}$ & Main fragments ion $(\mathrm{m} / \mathrm{z})$ & $\begin{array}{l}\text { Molecular } \\
\text { formula }\end{array}$ \\
\hline 1 & Citric acid & 1.603 & 191 & 111 & $\mathrm{C}_{6} \mathrm{H}_{8} \mathrm{O}_{7}$ \\
\hline 2 & $\begin{array}{l}\text { Trimethoxy flavone } \\
\text { derivative }\end{array}$ & 8.972 & 773 & $635,609,300$ & $\mathrm{C}_{40} \mathrm{H}_{38} \mathrm{O}_{16}$ \\
\hline 3 & Kaempferol & 9.110 & 285 & 151,93 & $\mathrm{C}_{15} \mathrm{H}_{10} \mathrm{O}_{6}$ \\
\hline 4 & Rutin & 9.27 & 609 & 300,271 & $\mathrm{C}_{27} \mathrm{H}_{30} \mathrm{O}_{16}$ \\
\hline 5 & $\begin{array}{l}\text { Hesperetin } \\
\text { glucoside }\end{array}$ & 9.433 & 463 & $301,300,271,97$ & $\mathrm{C}_{22} \mathrm{H}_{24} \mathrm{O}_{11}$ \\
\hline 6 & $\begin{array}{l}\text { Kaempferol- } \\
\text { coumaroyl-glucoside }\end{array}$ & 9.689 & 593 & $285,284,255$ & $\mathrm{C}_{31} \mathrm{H}_{30} \mathrm{O}_{12}$ \\
\hline 7 & Luteolin 3-glucoside & 9.724 & 447 & $285,284,255,227$ & $\mathrm{C}_{21} \mathrm{H}_{20} \mathrm{O}_{11}$ \\
\hline 8 & $\begin{array}{l}\text { Isorhamnetin-3-O- } \\
\text { rutinoside }\end{array}$ & 9.995 & 623 & $543,527,427,315,314$ & $\mathrm{C}_{21} \mathrm{H}_{36} \mathrm{O}_{21}$ \\
\hline
\end{tabular}

